\title{
Correspondence
}

Editor: Ian Pullen

Contents: Misuse of psychiatric terms/Confounds in CT studies of schizophrenia/Age of onset of depression in the elderly/Who benefits from lithium?/ The new genetics/'New chronics'/Is schizophrenia a G-I disease?/More on multiple personality disorder/ Life events and management in schizophrenia/ Pimozide in pathological jealousy/Zinc taste test and postnatal depression/Musical hallucinations.

\section{Misuse of psychiatric terms}

SIR: Psychiatrists frequently find that terms which apply to mental illness are used inappropriately by the media. Not uncommonly, newspaper articles include comments such as, " $\mathrm{Mr} \mathbf{X}$ is adopting a schizophrenic approach to this issue".

In Northern Ireland we have the added problem that pseudo-psychiatric terminology is employed by politicians, clergy, and others when speaking about terrorist violence. Members of the IRA, UVF, and UDA are variously described as "madmen", "mad dogs", "lunatics", "deluded", "mindless", "possessed", "mentally ill", "crazed", and "psychopathic". In commenting on a recent killing by the IRA, Neil Kinnock said, "The killing was not the work of a deluded activist but of a psychopath; someone who cannot possibly convince himself he is serving a political cause, but is undertaking an attack with such cruelty that he simply fulfils a bloodlust".

The reality, however, is that most Irish terrorists are neither mentally ill nor sociopathic. Lyons \& Harbinson (1986) compared terrorist murderers in Northern Ireland with other murderers. They concluded that the former exhibited significantly less psychopathology than the latter. Paramilitary killers had a much lower incidence of personality disorder in the family, were much less likely to have consumed alcohol prior to the murder, and had a lower incidence of mental illness $(16 \%)$ than non-terrorist murderers $(58 \%)$.

Members of the (nationalist) IRA and the (unionist) UVF and UDA are in general normal from the psychiatric point of view. They believe that they are fighting a just war. The recent television programme concerning the former and now repentant IRA letter bomber Shane Paul Doherty portrayed a young man who was and is inherently normal, but who responded intuitively to the sectarian subculture in which he was reared.

Politicians and clergy in Northern Ireland often try to avoid looking at the reasons why we have a sectarian society in which violence is endemic. Hence the recruitment of pseudo-psychiatric gobbledegook in an attempt to pretend (or wish) that violence occurs because of the mental instability or moral depravity of individuals. It is very similar to the Victorian attempt to sidestep embarrassing issues such as homosexuality by decreeing them to be a form of mental illness.

What can psychiatrists do about the misuse of psychiatric terms or concepts? Probably the most effective strategy is to write (politely) to the individual concerned and appraise him of the implications of such careless misuse. I shall therefore be sending a copy of this letter to Mr Kinnock.

\section{Purdysburn Hospital}

Philip J. McGarRY

\section{Reference}

LYONS, H. A. \& HARBINSON, H. J. (1985) A comparison of political and non-political murderers in Northern Ireland, 1974-1984. Medicine, Science and Law, 26, 193-198.

\section{Confounds in CT studies of schizophrenia}

SIR: Kaiya et al (Journal, October 1989, 155, 444 450) correctly assert that determining biologically distinctive subgroups of schizophrenic individuals is an important goal for modern psychiatry. In particular, the demonstration and successful discrimination of familial and non-familial forms of the illness would focus the search for disparate aetiologies in these subgroups, as well as inform the construction of pedigrees for molecular genetic analyses. To this end, Dr Kaiya et al report differences in ventricular: brain ratio (VBR) and sylvian fissure widening among controls and familial and non-familial schizophrenic individuals. 
While we applaud the approach taken, we find it difficult to interpret the reported results. We are wary of significance levels uncorrected for multiple comparisons, and of the use of controls screened to exclude those with cerebral abnormality as a comparison for scans without such screening. We are particularly concerned by the varying proportion of male and female subjects in the groups compared. Although the VBR measure attempts to correct for varying brain sizes by constructing a ratio of ventricular size to brain size, VBR varies positively as a function of brain size, which is in turn positively related to overall body size. Male subjects, generally larger than female subjects, have significantly larger VBR measures as well (Bridge et al, 1985).

An examination of the results of Dr Kaiya et al reveals that where differences in VBR are found between groups, there are also differences between the proportion of male subjects in these groups, with a larger proportion of males associated with larger VBR. The strength of this possible confound is indicated by calculating the correlation between the ratio of male to female subjects in a subgroup and the mean $V_{B R}$ (lateral ventricles $V B R$ ) reported for that subgroup; here $r=0.994, P<0.005$ for the nonfamilial, familial (horizontal), familial (vertical), and familial (mix) subgroups, and remains high ( $r=$ $0.963, P<0.005$ ) after including the control subjects.

It is my hope that by controlling intersubject variability due to gross physical differences such as height, continuing investigation of subtle differences between subgroups of schizophrenic individuals will reveal robust cerebral morphometric differences useful in elucidating the pathophysiological bases of schizophrenic illness.

LORING J. INGRAHAM

Laboratory of Psychology and Psychopathology National Institute of Mental Health Bethesda, MD 20892

USA

\section{Reference}

Bridge, T. P., Parker, E. S., Ingraham, L. et al (1985) Gender effects seen in the cerebral ventricular/brain ratio (VBR). Biological Psychiatry, 20, 1136-1138.

SIR: We were interested to read the study by Kaiya $e t$ al (Journal, October 1989, 155, 444-450). In common with similar studies, the use of high technology in psychiatric research seems to have excused the authors from sticking to the scientific conventions of a plausible, testable hypothesis which is adequately tested. Firstly, the hypothesis of three genetically dis- tinguishable sub-groups in the aetiology of schizophrenia has little or no precedent to our knowledge, nor much in the way of rationale. Secondly, the hypothesis is not tested properly. The control group was not, as might be expected, healthy volunteers, but neurology patients. They were collected retrospectively, were not matched for age or sex, and most surprisingly were not psychiatrically assessed. In addition, there is nothing to indicate that the multivariate analysis was performed with the intention of making planned comparisons. Consequently, the suggested associations between the CT findings in schizophrenic sub-groups may well be accidental.

It is a pity that with such a topical subject the study failed to be rigorous enough.

Paul Crichton

TIM HUGHES

Gordon Hospital

Bloomsbury Street

London SWIV $2 R H$

\section{Age of onset of depression in the elderly}

SIR: The interesting papers by Musetti et al (Journal, September 1989, 330-336) and Burvill et al (Journal, November 1989, 673-679) concerning depression in later life and age of onset prompted me to examine, in the light of their findings, data from a previously described cohort of elderly patients with major depression (Baldwin \& Jolley, 1986).

Details of whether the age of onset was before or after the age of 60 was available for all but two patients: 77 were late onset and 21 early onset. Lateonset patients were significantly older at the index admission than the early-onset group: 74.7 years compared with 71.5 years ( $t$-test, $P<0.01$ ). Unlike Dr Burvill et al I did not find that early-onset patients were more depressed, although the cohort as a whole were more severely depressed than theirs (Hamilton Rating Scale for Depression (17 item) scores: lateonset 27.8, early-onset 27.2; NS). However, like them, I found no significant differences in family history of depression. Twenty-three percent of the late-onset group $(n=62)$ and $21 \%(n=19)$ of the early-onset group had a positive history, although this data was missing on 17 patients. Likewise, there were no differences in the numbers dying or developing dementia during the follow-up period or in the overall outcome using the classification of Post (1972). Although adverse life events occurring in the previous 12 months were more common compared with the cohort of Dr Burvill et al, as in their study, the proportions did not differ significantly between the groups. Bereavement was the commonest event 